ISSN 1518-3483

Licenciado sob uma Licença Creative Commons

\title{
A docência no curso de pedagogia-licenciatura: o que dizem os professores sobre as Diretrizes Curriculares Nacionais
}

Teaching in the education training licensure programs:

what teachers say about the

National Curriculum Guidelines

\section{Helena Machado de Paula Albuquerque ${ }^{[a]}$, Celia Maria Haas ${ }^{[b]}$, Regina Magna Bonifácio de Araújo ${ }^{[c]^{*}}$}

\author{
[a] Pontifícia Universidade Católica de São Paulo (PUCSP), São Paulo, SP, Brasil \\ [b] Universidade Cidade de São Paulo (UNICID), São Paulo, SP, Brasil \\ [c] Universidade Federal de Ouro Preto (UFOP), Ouro Preto, MG, Brasil
}

\section{Resumo}

Este artigo apresenta o que dizem os professores que atuam nos cursos de Pedagogia, nas instituições envolvidas na pesquisa "O significado de ser Pedagogo para os alunos do novo curso de Pedagogia-Licenciatura", desenvolvida nos anos de 2010 e 2011, tendo como campo três universidades: uma instituição privada, uma municipal e outra federal, localizadas em dois estados da região sudeste do Brasil. Adotou-se no processo investigativo

* HMPA: Doutora em Educação, e-mail: helenaalb@uol.com.br CMH: Doutora em Educação, e-mail: celiahaas1@gmail.com EMBA: PhD, e-mail: regina.magna@hotmail.com 
uma metodologia com abordagem qualitativa, com pesquisa documental da legislação e dos projetos pedagógicos das instituições. Três categorias fundamentaram a investigação: o significado de ser pedagogo, o projeto pedagógico e o currículo e a nova legislação. Em 2006, foi aprovada a Resolução no 1, do Conselho Nacional de Educação, que instituiu as novas diretrizes curriculares nacionais para o curso de Pedagogia (DCNs). Conquanto, estas diretrizes, não tenham impedido a formação dos profissionais da educação, a dificultou pelo excesso de atributos exigidos na formação do professor. Os resultados da pesquisa apontam que nos cursos implantados após 2006, os professores percebem a incorporação do conceito de Profissional da educação na formação para a gestão no curso de Pedagogia. No curso mais antigo, os professores julgam que, embora as diretrizes não impeçam, inviabilizam na prática a formação do gestor e sentem dificuldade para se desvencilhar da cultura anterior do curso, mostram certa nostalgia em relação a esse e apontam que não houve a discussão necessária com quem iria implantá-las. Há uma concordância nos três grupos de que houve inovação nos projetos pedagógicos após a aprovação das diretrizes, destacando-se o esforço na integração teoria e prática e na ampliação do espaço para as metodologias de ensino da Educação Básica. A maioria dos professores entrevistados afirma que os projetos pedagógicos dos cursos em que atuam assumem a formação do licenciado com todos os requisitos previstos pelas DCNs. As instituições apresentaram em comum o desafio para articular a formação geral e específica do Pedagogo, contemplando todos os pré-requisitos oficiais para a formação do licenciado.

Palavras chave: Políticas públicas. Formação de professores. Diretrizes curriculares nacionais. Curso de Pedagogia. Docência universitária.

\section{Abstract}

This paper puts forward what teachers engaged in education courses in the institutions involved in the research on "The meaning of being an educator for the students of the new education training licensure programs," which was conducted between 2010 and 2011, having three universities - a private institution, a municipal and a federal one - located in the southeast of Brazil as its field, must say. A methodology with a qualitative approach was adopted in the research process, along with documentary research of legislation and the educational designs of the institutions. Three categories substantiated the research: 
the meaning of being an educator, the educational design and the curriculum, and the new legislation. In 2006, aligned with neo-liberal trends, Resolution No. 1 of the National Council for Education was passed. Such resolution instituted the new national curriculum guidelines for the education program (DCNs). Although it has not prevented the training of professionals in education, it has made it difficult because the excessive requirements on teacher training. The research findings indicate that in the newer programs, implemented after 2006, teachers become aware of the incorporation of the concept of Education Professionals in management training for education programs. However, in the earliest program, teachers believe that, although they do not cause an impediment, they prevent management training in practice, and they find it difficult to disengage from the previous culture of the program. They feel somewhat nostalgic about that program, and they consider that the new guidelines had to be hastily implemented, without the previous discussion required with the ones responsible for their implementation. There is an agreement among the three groups that there was innovation in educational projects after the adoption of the guidelines, especially the effort in integrating theory and practice and the expansion of leeway for elementary school teaching methodologies. Most interviewed teachers say that the educational projects of the programs in which they work take on the teacher training with all the requirements prescribed by the DCNs. All the institutions presented a challenge in common: to articulate the general and specific training of the educator, covering all the official pre-requisites for the teacher training.

Keywords: Public policies. Teacher training. National curriculum guidelines. Education program. College teaching.

\section{Introdução}

No Brasil, desde a promulgação da última Lei de Diretrizes e Bases da Educação Nacional, LDBEN 9394/96, esperava-se uma mudança no curso de Graduação em Pedagogia e, nessa perspectiva, desenvolveram-se vários estudos de diferentes grupos de educadores. No ano de 2006, foi publicada a Resolução CNE nº 1 , oficializando a proposta de novas Diretrizes 
Curriculares Nacionais para o Curso de Pedagogia, licenciatura, definindo-o como responsável pela formação de professores para a Educação Infantil e anos iniciais do Ensino Fundamental, para cursos de Ensino Médio, na modalidade Normal e para cursos de Educação Profissional na área de serviços e apoio escolar, bem como em outras áreas nas quais sejam previstos conhecimentos pedagógicos (Artigo $2^{\circ}$ ). Não impediram a formação dos profissionais da educação previstos no artigo 64 da Lei 9394/96, mas a dificultou pelo excesso de atributos exigidos na formação do professor. As Diretrizes privilegiaram a formação do professor, rompendo com a identidade de um curso que se voltava, até então, para a formação dos profissionais da educação e do professor, ambos indispensáveis para o funcionamento da Escola, exigindo uma nova compreensão e mudanças nas propostas para a formação do Pedagogo. Não propõem um perfil objetivo do Pedagogo, propiciando uma confusão dos atributos do professor e dos profissionais da educação.

As novas Diretrizes nacionais para o curso de Pedagogia, licenciatura representam uma reforma e expressam uma nova política. Para Gimeno Sacristán (1998) há muitos significados para reforma, podendo expressar, entre outros, programas para uma mudança geral do sistema ou uma ação para mudar um aspecto, como pode também significar uma ação ou várias de um governo para ocorrerem, em um tempo determinado, como medidas de uma política educativa. Para ele, as reformas situam-se em um ponto intermediário de tensão entre o existente e o desejável, neste sentido não consideram a realidade do sistema e nem as demandas dos que trabalham em educação e percebem as dificuldades cotidianas e as inadequações dos programas de reforma. Muitas reformas, com linguagem quase sempre pretensiosa, acabam desqualificando os saberes teóricos e práticos de bons professores (GIMENO SACRISTÁN, 1998).

Apesar de desejada uma reformulação do curso, a proposta pelas novas Diretrizes não deixou muitos educadores satisfeitos. Havia uma prática de formação, a qual se pretendia diferente, mas que não rompesse com o perfil do Pedagogo entendido como um cientista da educação com uma formação ampla e aprofundada que abarcava o conhecimento de 
fundamentos da educação e de conhecimentos técnicos, tornando-o capaz de um desempenho que incluísse, mas ultrapassasse a ação docente. E com elas surgem novos questionamentos sobre o curso.

Muitos questionamentos surgiram quanto ao significado de ser pedagogo para os alunos, entre eles, a dificuldade de implantação do novo curso, se o projeto pedagógico do curso alinhado às diretrizes estaria sendo fiel à área epistêmica da Pedagogia, qual seria a expectativa dos professores em relação à formação do Pedagogo, o grau de satisfação com a proposta, a facilidade e/ou dificuldade para incorporar as novas ideias e desenvolver uma ação coerente com a proposta. E imaginamos que dificilmente poderia se formar o Pedagogo, tal como sempre fora identificado, com as novas diretrizes.

Nesse contexto, desenvolveu-se nos anos de 2010 e 2011 a pesquisa "O significado de ser Pedagogo para os alunos do novo curso de Pedagogia-Licenciatura”, tendo como campo três Instituições de Ensino Superior (IES): uma privada confessional, uma municipal e outra federal, localizadas em dois estados da região sudeste do Brasil. Seu objetivo foi investigar, em instituições de educação superior, o novo projeto pedagógico do curso de Pedagogia na sua intencionalidade e prática, buscando identificar o significado de ser pedagogo para os alunos. Deste decorreram objetivos específicos: verificar o conhecimento dos alunos quanto às áreas de atuação do Pedagogo; explicitar em que medida o novo projeto pedagógico respeitou a área epistêmica da Pedagogia; verificar as dificuldades para implantação do novo projeto do curso; verificar a expectativa dos professores em relação à formação do Pedagogo e averiguar o nível de satisfação da instituição com a mudança.

Adotou-se na investigação uma metodologia com abordagem qualitativa, incluindo duas etapas, a primeira de pesquisa documental da legislação e dos projetos pedagógicos das instituições, estudo e análise de teóricos alinhados ao tema e subsidiários à compreensão histórica do curso e dos condicionantes que influenciaram a proposta e sua decorrente implantação e a segunda empírica. Foram sujeitos da pesquisa, ouvidos por meio de entrevistas e questionários, alunos, professores e gestores do curso 
em estudo nas universidades pesquisadas. Três categorias fundamentaram a investigação: o significado de ser pedagogo, o projeto pedagógico (PP), o currículo e a nova legislação. Neste artigo apresenta-se um recorte dos resultados, focalizando nos professores e o que dizem do curso de graduação em Pedagogia, quais dificuldades apontam, acertos e influências das novas diretrizes na revisão da concepção acerca desta formação e indícios de mudança na prática docente.

Os resultados apresentados foram construídos por meio da interlocução entre os dados coletados, a legislação e as ideias de alguns teóricos, alinhados ao tema. Saviani (2008), Chaves (1981) e Cruz (2011) subsidiaram a compreensão histórica do desenvolvimento da Pedagogia e do curso de Pedagogia, focalizando sob diferentes prismas. O primeiro no contexto da história da Educação brasileira, o segundo focalizando as diferentes regulamentações oficiais pelas quais passou o curso, e Cruz (2011) trazendo a história da formação por meio das memórias de Pedagogos de diferentes épocas. Todos evidenciaram que o curso sempre foi questionado, desde a sua primeira regulamentação em 1939, e que suas mudanças curriculares jamais foram neutras, sempre foram fruto do contexto social e histórico, sempre concebidas para atender objetivos específicos, reafirmando ideias de Goodson (1997) e de Apple (1989), para os quais a construção do currículo não é neutra, sempre é fruto do contexto social e histórico. Pablo Gentili e Silva (1995), focalizam o contexto social brasileiro com predominância da tendência neoliberal, no qual as necessidades humanas são subjugadas às do capital. Embora no estado brasileiro a tendência neoliberal não esteja tão arraigada como em alguns países europeus, as novas diretrizes se alinharam perfeitamente às leis do mercado predominantes na sociedade, ao enfatizarem a valorização técnica em detrimento da fundamentação teórica, dando abertura para a aquisição rápida de um diploma. Com o tecnicismo e o imediatismo, encolhe-se o espaço para o diálogo, para a reflexão, para o raciocínio moral e para a existência e desempenho do autêntico profissional. Ao estabelecerem a carga horária de 3200 horas (LDB9394/96, Artigo 7º), mas não a duração do curso, ensejaram o aligeiramento do processo de formação. Ball (2002), com os termos 
chave que cria de gerencialismo e performatividade, pelos quais ignoram-se as condições de trabalho e o desempenho de professores e gestores conforme o estabelecido, torna-se o principal responsável pelo sucesso da escola e favorece a compreensão da nova política educacional norteadora do curso de Pedagogia. Trata das políticas como tecnologias impositivas da perfomatividade esperada dos professores, pois, "dentro de cada uma das tecnologias políticas de reforma estão implantadas e estabelecidas novas identidades, novas formas de interação e novos valores" (BALL, 2002, p. 6). Lawn (2001) contribuiu na discussão das identidades dos professores propostas pelas políticas públicas, argumentando que tais alterações são um modo sofisticado de controle e uma forma eficaz de gerir mudança. Com base nesse autor percebeu-se que as novas Diretrizes Curriculares para o curso de pedagogia desenham uma identidade e propõem um "super professor" que, além de formar o cidadão, seja também capaz de sentir-se à vontade com as novas tecnologias, seja capaz de trabalhar em equipe, comprometer-se com a inclusão, tenha uma ação positiva no que se refere ao meio ambiente, atue interdisciplinarmente e assegure a aprendizagem em sala de aula. Novas e diversificadas competências foram citadas nas diretrizes que "criam uma cultura de excelência e de aperfeiçoamento do ensino” (LAWN, 2001, p. 128).

Com as novas Diretrizes Curriculares deveria ser construída uma nova prática, o perfil de Pedagogo mudara e a sua identidade fora rompida, a prática de formação precisaria atender a este novo perfil. Os professores do curso teriam que, necessariamente, mudar a sua prática docente e para isto teriam que mudar a respectiva ação, por meio da qual a pessoa e o profissional se expressam. Para Gimeno Sacristán (1999), a ação deixa sinais, vestígios e marcas naqueles que a realizam e no contexto interpessoal e social no qual ocorre, gerando efeitos, expectativas, reações, experiências e histórias que precisam ser evidenciadas e estudadas. As marcas da ação geram uma cultura subjetiva, por isto a necessidade de olharmos para as práticas educativas e vê-las enquanto ações sociais rotineiras, em sua diversidade, como sinal cultural do saber fazer. Para Gimeno Sacristán (1999, p. 82), "As práticas sociais são construídas, ou seja, prática da educação constituí-se em si mesma pela continuidade proporcionada pelo 'diálogo' entre as ações 
presentes e passadas dos indivíduos, do mesmo modo como é constituído o conhecimento sobre essas práticas". Sem uma prática pedagógica adequada dos formadores, não se propicia uma formação diferente aos estudantes. As ações individuais são expressões da pessoa, a qual se constitui pelos seus atos, pois, "o professor age como pessoa e suas ações profissionais o constituem” (GIMENO SACRISTÁN, 1999, p. 31). O indivíduo tem autonomia para agir, porém, sua ação traz a marca de ações anteriores, que vai gerando uma cultura subjetiva, esquemas para novas ações, prática pessoal, fruto das várias ações, do aprendizado e experiência. Nenhuma ação nasce do nada. As ações podem ser imitadas e compartilhadas, gerando a realidade social, dando estabilidade à ação de cada um e possibilitando projetos coletivos. As atividades geram uma bagagem cultural, uma prática ou cultura da prática, sempre sujeitas a aperfeiçoamentos. No curso de Pedagogia já havia uma prática constituída, ou seja, um habitus (BOURDIEU, 1991), fruto do acúmulo cultural historicamente construído, alheia a forma de conceber o novo curso proposto pela Resolução no 1/2006 e a construção de uma nova prática educativa pelos educadores do curso de Pedagogia exigiria um tempo incompatível com o aligeiramento implícito nas diretrizes e poderia gerar resistência à proposta. No cotidiano de trabalho será possível contribuir para a reprodução ou valer-se da tradição no sentido dinâmico de transformação, para instaurar uma prática pedagógica adequada ao novo projeto. Todavia, jamais ocorrerá um esquema inédito, sem vinculação com os esquemas de ação construídos no decorrer das ações docentes anteriores. Existem estruturas definidas, embora sempre haja espaço para decisões pessoais e a realidade social estável é proporcionada pelo habitus, conceito construído por Bourdieu (1991). A força do habitus permite agir sem planejamento, garante a continuidade, embora reprodutor, dá margem à possibilidade de inventar dentro dos limites das regularidades dele decorrentes.

As novas Diretrizes tiveram que ser imediatamente respeitadas e um novo projeto pedagógico teve de ser construído com outra formatação curricular, coerente com o que nela estava previsto, ou seja, uma matriz curricular com uma estrutura organizativa constituída de três núcleos: de estudos básicos, de aprofundamento e diversificação de estudos e de estudos 


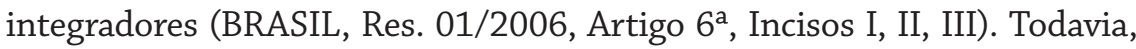
uma mudança educativa não acontece de imediato, em decorrência da lei, conforme Gimeno Sacristán (1998).

Para Lima (2001) que se vale de alguns modelos teóricos, privilegiando o racional e o anárquico, para análise das organizações escolares, estas sempre fazem adaptações das leis às suas realidades específicas. As organizações escolares estão sujeitas a normas e determinações do sistema, deve obediência aos órgãos superiores, à legislação e às políticas educacionais, apresentam uma estrutura de cargos e funções, sofrendo a influência de fatores históricos, políticos, sociais, econômicos internos e externos. Não se submete, porém, ao modelo estritamente racional, mas se organiza conforme as demandas do cotidiano de trabalho. Simultaneamente, a racionalidade assume o modelo de "uma anarquia organizada", a qual, não significa desorganização, mas a separação entre objetivos, estruturas, recursos, atividades e produção de "regras alternativas, onde ora se respeita a conexão normativa, ora se rompe com ela" (LIMA, 2001, p. 47). A escola não se submete às normas oficiais, ela faz adequações, adaptando-as à sua realidade, e até cria novas normas (LIMA, 2001). Da mesma forma que a escola de Educação Básica, a instituição de ensino superior faz adaptações e cria novas regras a partir das normas oficiais.

Para a realização da pesquisa, seminários de estudos foram contínuos durante todo o processo, e outros teóricos foram chamados conforme se faziam necessários pelas próprias demandas do processo.

\section{Características e dados de cada instituição investigada}

As instituições pesquisadas construíram projetos diferenciados, embora cumprindo a mesma legislação, pois cada uma os adaptou às suas realidades específicas. Os projetos apresentam pontos comuns e diferenças no esforço de cada instituição para atender às exigências legais, respeitando as peculiaridades próprias, considerando o contexto educacional e 
social do curso e a cultura local, de acordo com o que afirma Lima (2001, p. 8) quanto à ação organizacional:

[...] ora se apoiarão na ordem das conexões normativas e da conformidade burocrático-racional, ora promoverão a ordem das desconexões relativas, muitas vezes vista como desordem pela primeira: lócus de reprodução normativa, a escola será também um lócus de produção de orientações e regras (grifo do autor).

Portanto, cada proposta apresenta diferenças resultantes da interpretação da norma legal, sem incorrer em ilegalidade, o que mostra que a legislação depende do entendimento de quem a lê (BALL, 2002).

\section{A Instituição Privada Confessional}

O curso de Pedagogia da instituição privada confessional está localizado na Faculdade de Educação. Reconhecido oficialmente em 1940, vivenciou muitos processos de mudanças legais e institucionais. Oferecia várias habilitações, ou seja, oportunidade para aprofundamento de estudos em áreas de formação específica: docência das disciplinas dos Cursos Normais, orientação e supervisão educacional, administração Escolar, magistério, para formar professores para os anos iniciais do Ensino Fundamental, e Educação Infantil, até a publicação das novas diretrizes, que as extinguiu. $\mathrm{O}$ novo projeto pedagógico respeita a legislação, privilegia a licenciatura, mas enfatiza também a formação do gestor, que era considerada de muita qualidade no projeto anterior, aproveitando a limitada possibilidade que as Diretrizes Curriculares Nacionais oferecem para o bacharelado, por meio da possível formação desse profissional (CNE/CP No 1/2006, Art. 14).

O atual projeto teve inicio em 2007 e, sob essa nova organização, a primeira turma concluiu o curso em 2010. Apresenta como perfil profissional desejável o de formar um Pedagogo - docente que se constitua 
não só como um profissional da educação, mas também, como cidadão consciente e comprometido com seu tempo, sensível às emergências sociais e que se disponha às interações possibilitadoras de mudanças (PROJETO PEDAGÓGICO, 2006, p. 83).

A proposta articula a licenciatura - preparação para a docência na Educação Infantil, nos anos iniciais do Ensino Fundamental e na Educação de Jovens e Adultos (EJA) e o bacharelado — formação do profissional de gestão, embora, por vezes, articulada à formação do professor e à preparação para atuar nos espaços escolares e não escolares: empresas, Organizações não Governamentais (ONGS) gestão hospitalar. O curso foi previsto para um período de quatro anos, com 3200 horas. Tem como objetivo formar profissionais com

[...] uma com sólida formação teórica e interdisciplinar sobre o fenômeno educativo e seus fundamentos filosóficos, históricos, políticos e sociais, práticas de intervenção e pesquisa voltadas para a escola brasileira e outros espaços educativos, propondo a solidariedade e o compromisso com a transformação (Idem, 2006, p. 87).

A organização curricular, afastando-se de uma concepção de disciplinas, busca superar a dicotomia teoria-prática pela inter, multi e transdisciplinaridade, para evitar a fragmentação do conhecimento. Estimula professores e alunos a reverem seu próprio processo de formação e a pensarem criticamente formas de reorientá-lo, de acordo com as necessidades formativas atuais. São assumidos como princípios norteadores a "flexibilidade e interdisciplinaridade, ao longo do curso; formação multidisciplinar para enfrentar os desafios da educação básica e das diferentes modalidades surgidas na sociedade e a construção de competências para esse novo profissional" (PROJETO PEDAGÓGICO, p. 141-142). Estimula-se a postura de investigador, propondo-se a constante reflexão sobre a própria ação e os professores são chamados a trabalhar "totalmente articulados nas diferentes unidades temáticas e atividades interdisciplinares", sem esquecer as Tecnologias de Informação e Comunicação (Idem, 2006, p. 142). Articulada às linhas de pesquisa da Faculdade de 
Educação e dos Programas de Pós-Graduação, a prática investigativa percorre os quatro anos de formação, tendo como produto final a elaboração do Trabalho de Conclusão de Curso (TCC).

A proposta curricular contempla três núcleos: estudos básicos, aprofundamento e estudos integradores. Organizam-se em quatro módulos, cada um compreendendo dois eixos. "Os eixos representam um conjunto de saberes que transversaliza o desenho curricular, garantindo o entrelaçamento e a nuclearidade das unidades temáticas" (PROJETO PEDAGÓGICO, 2006, p. 154). Os conteúdos são organizados em unidades temáticas e não em disciplinas isoladas. Em cada semestre, a carga horária é de 400 horas, divididas em unidades temáticas de 80 ou de 40 horas/aula, distribuídas em 18 a 20 semanas. O currículo tem uma oferta ampla de unidades temáticas, visando assegurar a formação do pedagogo-docente, do profissional da educação e do cidadão consciente e comprometido com seu tempo, sensível às emergências sociais, sujeito e agente do processo cultural e capaz de participar na transformação das relações de poder, o que configura uma formação marcada pela dimensão político-social. Aponta a preocupação com um projeto de sociedade, na qual todos tenham acesso aos bens materiais simbólicos e o compromisso prioritário com a escola pública como espaço privilegiado para a democratização do saber. As competências e habilidades, descriminadas no corpo do projeto, devem ser atendidas pelos eixos temáticos. O projeto pedagógico do curso contempla os núcleos, eixos temáticos e atividades de extensão como forma de inserção dos alunos na realidade da Educação Básica.

\section{O que afirmam os professores}

Dos 18 docentes convidados do último ano, delimitado para a pesquisa, 10 aceitaram ser entrevistados.

O significado de ser pedagogo para os professores é de um bacharel e licenciado, duas funções específicas, mas complementares e que têm como campo 
de trabalho, além do escolar, as diferentes áreas não escolares indicadas no projeto, embora conforme afirmação dos professores, isso não esteja ocorrendo. Não de modo adequado por influência das diretrizes, as quais visam a formação do professor, apenas como complemento é que faz referência às outras áreas de atuação, incorporou as ciências da educação equiparado ao antigo bacharelado, mas a licenciatura predomina (Afirmação de um professor).

Os dados indicam que na prática, não está havendo equilíbrio entre as duas formações. O perfil do Pedagogo é focado na docência, prioritariamente, da Educação Infantil e a formação do gestor claramente prevista no projeto, não ocorre, bem, como para trabalhar em ambientes não escolares (Fala de um professor).

Os dados evidenciam o reconhecimento de que o curso está transmitindo para a maioria dos alunos a visão de Pedagogo apenas professor e que não conseguem o aprofundamento teórico que gostariam (ALBUQUERQUE, HAAS, ARAUJO, 2011). Para a maioria dos professores, as diretrizes foram construídas alinhadas à tendência neoliberal, restringiram a formação, não havendo uma definição clara do Pedagogo. Para um professor, seria suficiente se o curso assumisse a formação do professor para os anos iniciais do Ensino Fundamental.

De acordo com os docentes, o curso teoricamente é bom, mas não está havendo coerência com o funcionamento na prática e é influenciado pela postura dos professores e alunos. Para os docentes, os alunos não possuem formação básica quando entram, enquanto os professores nem sempre são fieis às ementas das unidades temáticas, alguns são pouco exigentes, não oferecem desafios para os alunos e não os avaliam continuamente (Idem, 2011). Para os docentes, o curso apresenta inovações: oportunidade de estudos de novas tecnologias em educação; estudo da gestão escolar em diferentes contextos, ao longo do curso; professores de outras faculdades ministrando as metodologias específicas; a organização do currículo em eixos temáticos e o rompimento com a disciplinaridade, sem o abandono dos conteúdos disciplinares. No entanto, expressam a dificuldade de colocá-lo em prática pelas demandas que provoca, como trabalho conjunto, planejamento e replanejamento contínuo. Falta 
integração e diálogo entre alunos e professores e entre professores, articulação entre os eixos temáticos, trabalho coletivo, integrado, sendo o espaço organizacional e físico da universidade um dificultador para que tudo isso ocorra. Acresce-se o fato de que não se desenvolve por alguns uma análise crítica do currículo, que inclua a denúncia e o anúncio de alternativas de solução. Percebem inovações, o que é positivo, porém mostram-se um pouco angustiados com todas as mudanças, e isso não está sendo discutido.

Um dos professores afirma, ao final de sua entrevista: Perdoe o que possa parecer ter sido um desabafo. Esta fala mostra que, apesar das reuniões sistemáticas dos professores do curso e zelo da coordenação, está fazendo falta um diálogo, pelo qual se sintam livres para expressar o que pensam, desejam e pelo qual busquem alternativas de solução para os problemas, condições para germinar e construir um grupo docente integrado, estimulando uma participação ativa no processo. Na visão de Lima (2001), a participação ativa é caracterizada por:

[...] atitudes e comportamentos de elevado envolvimento na organização, individual ou coletivo. Traduz capacidade de mobilização para a ação, conhecimento aprofundado de direitos, deveres e possibilidades de participação, atenção e vigilância em relação a todos os aspectos considerados pertinentes, afirmação, defesa e alargamento das margens de autonomia dos atores e da sua capacidade de influenciar as decisões [...] (LIMA, 2001, p. 77).

Para alguns professores, o curso perdeu a qualidade e retrocedeu. Quanto à nova legislação, alguns professores desconhecem as Diretrizes Curriculares. A imposição externa das Diretrizes e de sua aplicação imediata para evitar a suspensão do curso, subtraiu o tempo para um estudo e análise aprofundados o que, aliado a não participação direta na construção do novo projeto pedagógico, elaborado apenas por uma comissão, transformou-se num fator dificultador para a aceitação do projeto e para uma ação coerente com os seus objetivos e características. A indefinição pelas diretrizes do perfil de formação que defende, 
privilegiando o de licenciado, mas não descartando a formação do bacharel, imprimiu uma complexidade maior para a construção do projeto do curso e para o trabalho docente.

A reforma do curso está mexendo com a subjetividade do professor. "A reforma não muda apenas o que nós fazemos. Muda também quem nós somos" (BALL, 2002, p. 5). Subjacente às suas respostas, percebe-se que muitos professores estão procurando responder as demandas do currículo novo, mas estão incomodados por se afastarem de um currículo que julgavam excelente, expressando, dessa forma, que a política educacional de fato provoca mudanças tanto na instituição quanto nas subjetividades, no modo de se perceber e agir como professor (BALL, 2002). Os professores estão descontentes e estão atuando dentro da nova lógica de organização do curso, sem aceitá-la e sem compreendê-la totalmente. A maioria tem clareza tão somente da necessidade de reformulação das diretrizes e do projeto pedagógico da instituição, pois ambos não atendem às suas expectativas.

\section{A Instituição Municipal}

O Curso de Graduação em Pedagogia - licenciatura, da Instituição Municipal foi concebido em 2006, de acordo com as normas das Diretrizes Curriculares atuais e reconhecido legalmente em 2009. Em 2006, implantou-se o curso com uma organização seriada anual e duração de quatro (4) anos letivos. Em 2010, a estrutura foi revisada, quando se passou a oferecê-lo com a duração de seis semestres e com uma organização seriada modular.

Em consonância com as novas diretrizes curriculares, destaca-se o propósito da Licenciatura em Pedagogia de formar o professor para o exercício da docência na Educação Infantil e nos anos iniciais do Ensino Fundamental, nos cursos de Ensino Médio, na modalidade Normal, e em cursos de Educação Profissional na área de serviços e apoio escolar. Da mesma forma, a licenciatura em Pedagogia habilita também o Gestor 
Escolar. "A proposta do curso de Pedagogia é oferecer uma sólida base em conhecimentos didático-pedagógicos, de planejamento, controle, direção, organização, gerenciamento das atividades escolares e de prática do ensino" (PROJETO PEDAGÓGICO, 2011, p. 21).

O objetivo em relação à definição do perfil profissional explicita que o curso de Licenciatura em Pedagogia da Instituição Municipal busca formar pedagogos preparados para o desempenho da docência em espaços educativos formais e não formais. Visa um profissional com sólida formação teórica, técnica, científica e pedagógica, que compreenda a multidimensionalidade do processo educativo - a dimensão humana, técnica e política que esteja comprometido com seu contínuo aperfeiçoamento teórico-prático, um profissional capaz de investigar, refletir, gerar conhecimento, gerir e ensinar tanto no âmbito escolar, como em espaços não escolares.

A organização curricular compõe-se de três núcleos interdisciplinares, conforme as Diretrizes. Esses articulam entre si o ensino, o desenvolvimento da pesquisa e a formação profissional, em atendimento ao que propõe a Resolução ${ }^{0} 1 / 2006$ em seu Art. $3^{\circ}$ — "a pesquisa, como foco no processo de ensino-aprendizagem, uma vez que ensinar requer tanto dispor de conhecimentos e mobilizá-los para a ação como compreender o processo de construção de conhecimento" (BRASIL, 2006).

O curso de Licenciatura em Pedagogia está estruturado em disciplinas com características interdisciplinares, atividades teórico-práticas de aprofundamento, atividades complementares de formação profissional e estágios supervisionados, perfazendo uma carga horária total de 3600 horas aula e 3220 horas de efetivo trabalho acadêmico. Nos estágios supervisionados, proporcionam-se vivências por intermédio de um currículo flexível, para que o aluno, futuro professor, exercite suas capacidades de observação crítica e exercício profissional. No conjunto das disciplinas, 480 horas aula são de didática, o que junto com conteúdos e práticas das áreas de matemática, ciência, história e geografia, educação física e língua portuguesa e mais de alfabetização e letramento, todas com 160 
horas, expressam a opção do curso pela formação do professor (PROJETO PEDAGÓGICO, 2011).

Explicita dois compromissos: a integração teoria e prática e a busca de uma formação interdisciplinar, que provoque e imponha ao conjunto de professores formadores "o movimento de integração entre as áreas de conhecimento, ao mesmo tempo, em que desencadeia um processo de revisão e atualização dentro de cada uma das disciplinas" (PROJETO PEDAGÓGICO, 2011, p. 24). Dessa integração espera-se como resultado a ampliação dos "espaços de intercâmbio dinâmico e experiências pedagógicas inovadoras na tentativa de construir uma leitura integrada da ação docente" (Idem, 2011, p. 24).

Assegurando a integração entre teoria e prática, promove-se a preparação de protagonistas, propõe-se o desenvolvimento da autonomia intelectual do aluno e busca-se propiciar uma formação de professores com condições para a pesquisa, em permanente reflexão de sua ação educativa.

\section{O que afirmam os professores da Instituição de Ensino Superior (IES) Municipal}

Convidados todos os doze professores que atuam no curso de Pedagogia, oito espontaneamente se dispuseram a participar da pesquisa, respondendo às questões da entrevista.

Sobre o significado de ser pedagogo, os professores concordaram que a maior expectativa é a formação docente e entendem esta como "base para a formação do pedagogo". A metade dos entrevistados (4) indicou que a gestão compõe o significado do pedagogo e reconheceram a dificuldade de tal formação com as atuais diretrizes curriculares e, mesmo admitindo que o curso "de pedagogia como lugar privilegiado da fundamentação teórica e a busca na consolidação das práticas, pelas metodologias", apontaram a necessidade de se repensar a integração teoria e 
prática e a compreensão do que seria um projeto pedagógico interdisciplinar (ALBUQUERQUE, HAAS, ARAUJO, 2011, p. 38, 2011, p. 38).

$\mathrm{Na}$ época da proposição do projeto pedagógico do curso de pedagogia da IES Municipal, não havia uma equipe com condições de tal construção, e, portanto, o projeto foi concebido e construído pela atual coordenadora do curso. Essa construção foi antecedida por um diagnóstico institucional, fruto do compromisso da IES Municipal, expresso em seu PDI, e que retrata sua vocação acadêmica de formação de docentes. A proposta de um novo currículo só contou com a construção coletiva dos primeiros docentes desse curso, a partir de 2007, quando se iniciou a $1^{\text {a }}$ turma.

A partir das respostas coletadas, depreende-se que na IES Municipal o significado de ser pedagogo é explicitado na docência, o que é coerente com o projeto pedagógico do curso, que tem intencionalmente o propósito de uma formação compatível com a importância e complexidade da atividade de ensino em todos os níveis definidos pela lei. Também se manifesta uma preocupação com a formação do pedagogo-professor, tratando da formação do bacharel em gestão escolar como uma temática secundária. Ao definir o perfil, busca-se o expresso no projeto pedagógico (ALBUQUERQUE, HAAS, ARAUJO, 2011, p. 38-42).

Ball (2002, p. 3), no texto "Reformar escolas/reformar professores e os terrores da perfomatividade", busca compreender "as subjetividades das mudanças e as subjetividades em mudança", reconhecendo nas políticas públicas os mecanismos para tais mudanças que trazem proposições para reformar os professores e uma maior mudança subjetiva, que é a mudança do que significa para o sistema e para cada um ser professor. Destaca ainda a insegurança e o estranhamento que tais políticas/tecnologias causam nos professores e afirma que "as tecnologias políticas do mercado, gestão e performatividade não deixam espaço para um ser ético autônomo ou coletivo" (Idem, p. 19). 
Quanto ao projeto pedagógico e ao currículo, a maioria dos professores entrevistados considera que o curso incorporou o conceito de bacharelado, mas não há concordância de como tal formação acontece no curso, o que indica que os professores, formados por cursos organizados no modelo tradicional dicotômico, não têm clareza das possibilidades de assegurar a formação integrada que as novas diretrizes instituíram. A quase totalidade dos professores entrevistados considera o projeto pedagógico da IES Municipal inovador, considerando como indicadores as disciplinas de metodologia, a proposta da interdisciplinaridade e os projetos que o curso propõe para a participação dos alunos. Dos oito professores participantes da pesquisa, só um acredita que o curso consegue formar também o bacharel em gestão escolar, o que demonstra que tal formação não fica explícita no projeto pedagógico ou na matriz curricular. Um professor não reconhece nenhuma inovação, mas admite o correto atendimento às diretrizes curriculares.

Os professores nas entrevistas evidenciam a nova identidade que o Pedagogo assume nas diretrizes, em que pese não estar muito objetiva a não ser quanto à expectativa de formação do "super professor" e que mexe também com a identidade do docente que irá formar este novo pedagogo, confirmando o pensamento de Lawn (2001).

Quanto à nova legislação, os professores consideram que o curso atende às diretrizes curriculares, mas destacam que tal mudança levará um tempo para ser compreendida. Consideram que o maior desafio é a articulação entre a fundamentação necessária e a formação específica para tantas funções que, hoje, são atribuídas ao pedagogo. As novas diretrizes atendem às expectativas dos professores, fundamentalmente, em relação ao papel atribuído ao curso na formação de professor. A formação do gestor não está presente na fala dos professores.

Os professores respondentes concordam que as diretrizes curriculares são confusas, porque tentaram atender às diversas demandas da área de formação de professores e abandonaram a concepção do pedagogo. Hoje, o curso forma o professor e não mais o pedagogo. O que se precisa discutir melhor é qual o papel do pedagogo, no sentido da possibilidade 
de existência de um espaço no sistema para ele. Também, ainda se deve pensar com muito cuidado na formação do professor da Educação Infantil e primeiro ciclo do Ensino Fundamental e se este pode ser o gestor ou coordenador ou ocupar outra função na escola. As duas formações juntas, com qualidade, não parecem ser possíveis para o conjunto dos professores da Instituição Municipal.

\section{A Instituição Federal}

O curso de Pedagogia da Instituição Federal, fundada em 1969, embora desejado pelos educadores, foi criado somente no segundo semestre de 2008, com a conclusão da primeira turma de 2012. O curso se inscreve no Departamento de Educação, que faz parte do Instituto de Ciências Humanas e Sociais, e integra-se ao Programa de Reestruturação e Expansão das Universidades Federais - REUNI. Proporciona ao egresso uma formação para a docência na Educação Infantil, nos anos iniciais do Ensino Fundamental e nos cursos de Ensino Médio. Na modalidade Normal, oferece uma formação que possibilita ao pedagogo atuar na gestão pedagógica, administrativa e financeira de instituições escolares e em outras áreas, nas quais sejam previstos conhecimentos pedagógicos (PROJETO PEDAGÓGICO, 2008, p. 14).

Sua matriz curricular se divide em três núcleos: básico, de aprofundamento e diversificação de estudos e de estudos integradores. Este último com a preocupação de articular os processos teóricos e práticos, compreendendo atividades de pesquisa, práticas pedagógicas, atividades científico-culturais e estágios. O projeto pretende a formação de um profissional com perfil amplo e generalista.

Nessa matriz curricular, são apontados 22 atributos relacionados a competências, posturas, habilidades, conhecimentos, compromissos, incumbências do profissional, num excesso que oscila entre a formação estritamente docente e a formação do gestor. Destaca-se a necessidade de 
[...] instrumentalizar o espaço acadêmico para os estudos sistemáticos e avançados na área de educação, as necessidades da comunidade local e a ampliação da oferta de educação superior, o compromisso na formação do profissional da Educação Infantil e anos iniciais do Ensino Fundamental, nos cursos de Ensino Médio, Normal e Profissional nas áreas de serviços e apoio escolar e em outras áreas, capaz de atuar na organização e gestão de sistemas, unidades e projetos educacionais e na produção e difusão de conhecimentos, em diversas áreas da educação (PROJETO PEDAGÓGICO, 2008, p. 14).

O curso está organizado em 8 semestres letivos, com 3200 horas, e tem na proposta disciplinar previsão de pré-requisitos, próprios do modelo de créditos. Busca-se, durante o curso, a interação teoria-prática na formação humana e na relação com os saberes profissionais, a pesquisa é concebida como princípio cognitivo e a integração dos conhecimentos se dá numa perspectiva coletiva, multi e transdisciplinar para o entendimento da complexidade do real. Estão previstas 2580 horas para disciplinas teóricas e/ou práticas, 220 horas para atividades científico-culturais, 100 horas para atividades teórico-práticas de aprofundamento e 300 horas para estágio supervisionado, que se inicia no segundo semestre letivo.

A proposta enfatiza o compromisso com a comunidade por meio da abertura dos estágios para as escolas públicas da região e inova, ao considerar a articulação teoria-prática como eixo central do currículo, caracterizado pela flexibilidade, com uma extensa lista de disciplinas eletivas, propiciando melhor atendimento às expectativas e necessidades de formação do aluno. Apresenta uma lista de 31 disciplinas eletivas, cuja maioria está voltada para a formação do professor. A formação do gestor escolar, supervisor e planejador é realizada por meio de disciplinas, na sua maioria, eletivas. Apenas no primeiro ano é obrigatória a disciplina Política Educacional, com 60 horas, cuja ementa e plano de ensino contemplam conteúdos necessários à formação tanto do licenciado, quanto do bacharel. A tendência está voltada para formação do licenciado e não do bacharel.

O currículo do curso de Pedagogia se organiza em núcleos e eixos temáticos, tentando superar a organização disciplinar tradicional. A prática pedagógica é assumida como um trabalho coletivo que exige a "participação 
de todos os professores responsáveis pela formação do pedagogo na formação teórico-prática de seu aluno" (PROJETO PEDAGÓGICO, 2008, p. 7).

No currículo são enfatizadas as disciplinas de políticas públicas e sociologia e se destaca o ponto de convergência: o empenho e compromisso com uma excelente formação inicial do professor. Pelos dados da pesquisa, não se pode afirmar que isso foi alcançado, isso só poderá ser confirmado no acompanhamento dos egressos e de suas ações na docência.

\section{O que afirmam os professores}

Os dados foram coletados, por meio de entrevistas, e participaram cinco professores, sendo um deles chefe do Colegiado de Pedagogia, cargo equivalente, na estrutura da Instituição Federal, ao de coordenador de curso. A participação de dois professores de outros departamentos (Biologia e Letras), mas que ministram no curso disciplinas específicas contribuiu com as reflexões. Quanto à categoria "o significado de ser pedagogo", para este grupo de professores a formação do pedagogo deve assegurar a formação de um profissional capaz de atuar no processo educacional de modo a prepará-lo para planejar, executar e, ainda, qualifica-lo para interferir e fazer as mudanças sempre que necessário. A expectativa é a de formar o professor para atuar na Educação Infantil, nos anos iniciais do Ensino Fundamental, na Educação de Jovens e Adultos e em outras áreas específicas da educação. Um profissional que leve em consideração os conhecimentos sobre currículo, organização escolar, processos de ensino e aprendizagem, gestão e conhecimentos sociais. Para dois professores, a expectativa é que o pedagogo vá atuar em diferentes áreas profissionais, principalmente no contexto educacional.

Dos cinco docentes entrevistados, três reafirmam a importância da formação prevista nas Diretrizes, ou seja, atuar na docência e na gestão de espaços escolares e não escolares. Um dos professores declarou que não existe um campo específico de atuação do pedagogo e que este ainda não conseguiu construir uma categoria profissional que lute por mudanças na 
carreira, por melhores salários e campo de atuação. Para este professor, a legislação fechou o campo de atuação do Pedagogo, ao invés de ampliá-lo. Em relação ao projeto pedagógico e o currículo, três professores assinalaram que a formação prevista incorporou o conceito de bacharelado na licenciatura. Um declarou que a formação prevista não incorporou este conceito e outro declarou não ter condições de responder esta questão. De acordo com um dos professores,

se entendermos o bacharelado como uma formação específica para pensar uma determinada área do conhecimento, a formação prevista o incorpora, pois a licenciatura não pode ser apenas o fazer pedagógico, mas tem que se concentrar também no saber fazer e no pensar sobre o fazer (ALBUQUERQUE, HAAS, ARAUJO, 2011, p. 40).

Entretanto, para um dos professores, o projeto não contempla a formação do docente para a Educação Infantil, ao não ofertar: nenhuma disciplina sobre a organização da Educação Infantil, sobre práticas pedagógicas da Educação Infantil, nem disciplinas sobre a infância, sobre história da infância ou psicologia da infância, reforçando a pesquisa de Bernadete Gatti (2010) que encontrou apenas 3,8\% de disciplinas relativas à Educação Infantil, nas escolas investigadas. Somente um professor declarou que houve inovações, como a

incorporação de práticas de pesquisa, monitoria, entre outras, como componentes curriculares, apesar de compreender que essas inovações, por si, não garantem uma formação mais completa do aluno egresso, pois elas devem ser acompanhadas de perto, com olhar atento, para que se torne parte efetiva do processo de formação do graduando, e não somente mais uma carga horária a ser cumprida (ALBUQUERQUE, HAAS, ARAUJO, 2011, p. 38-42).

Quanto ao projeto pedagógico e à nova legislação, um dos professores entrevistados declarou que o projeto assume a formação do licenciado com todos os requisitos previstos nas Diretrizes, apesar de privilegiar alguns requisitos. Outro afirmou "o projeto pedagógico do Curso 
de Pedagogia da Instituição Federal atende aos requisitos previstos nas Diretrizes. Assim, alguns requisitos aparecem no projeto, mas não são desenvolvidos de forma aprofundada" (ALBUQUERQUE, HAAS, ARAUJO, 2011, p. 38-42).

Dos cinco professores, somente um declarou que as Diretrizes atenderam à sua expectativa, pois configuraram uma formação mais ampla do Pedagogo, apesar de ocorrer o privilégio de alguns conhecimentos em detrimento de outros. Para outro, as Diretrizes não corrigem um problema histórico do curso, que é dar uma identidade ao Pedagogo e, em momento nenhum, define o que é Pedagogia e, ao invés de usar o termo "pedagogia", usa o tempo todo o termo professor, trazendo confusões na definição do que é ser professor e do que é ser pedagogo.

Merece destaque a fala de um dos professores, ao afirmar que as Diretrizes parecem, sim, apontar para uma formação mais ampla do pedagogo, mas reconhece que, como alguns aspectos aparecem apenas indicados, é possível abordá-los de forma mais superficial ou mais profunda, segundo escolhas feitas.

[...] acho que algumas coisas, que são fundamentais na formação pedagógica, deveriam ser mais bem delineadas, sem tanta abertura, por exemplo, não se fala de modo claro nos conhecimentos específicos sobre a alfabetização, o que, a meu ver, deveria estar mais explícito (ALBUQUERQUE, HAAS, ARAUJO, 2011, p. 38-42).

Um desafio fica evidente no conjunto das respostas dos professores: a formação do Pedagogo-professor vai exigir, seja do curso, seja do Departamento de Educação, uma ampla revisão do seu projeto, bem como maiores discussões sobre o modelo que a instituição pretende adotar, de uma maneira geral, para a formação de professores. Um modelo que se concentra no domínio específico de conteúdos das áreas com as quais o docente irá trabalhar ou se é necessária uma efetiva formação pedagógica, que contemple todos os compromissos propostos pelas Diretrizes. 


\section{Considerações finais}

Os dados coletados nas entrevistas com os professores das três instituições indicam que a autonomia do professor está sendo limitada não só pelas dificuldades apontadas, mas pelo apego ao conhecimento que dominam e à importância que conferem à ação docente isolada e limitada por este conhecimento.

No curso de Pedagogia já havia uma prática constituída, ou seja, um habitus (BOURDIEU, 1991), fruto do acúmulo cultural historicamente construído, alheia à forma de conceber o novo curso proposto pela Resolução $n^{0} 1 / 2006$, o que talvez possa explicar o porquê de muitas resistências. Uma prática pedagógica, adequada ao novo projeto, poderá ser instaurada, mas sempre será vinculada ao esquema anterior de ação que fora construído ao longo do tempo. Para Gimeno Sacristán, "as práticas educativas objetivas, consolidadas pelos processos de estruturação institucionalizada e pelo habitus são múltiplas" (GIMENO SACRISTÁN, 1998, p. 6) e a prática coletiva resulta de ações individuais que vão ocorrendo, cada uma refletindo a lembrança, a experiência e o que aprendeu da ação anterior. Os professores já tinham uma prática que resultou desse movimento histórico e, de repente, por força da norma legal, necessitam mudá-la. A mudança coletiva só ocorre com a mudança da ação individual (Idem, 1998), o que não é fácil e não acontecerá rapidamente.

$\mathrm{Na}$ visão dos professores, as diretrizes romperam com uma identidade já cristalizada do curso e impôs outra que ainda não foi incorporada e assumida, porque está por ser construída, dificultada por fatores como: a ambiguidade expressa do perfil de licenciado e bacharel, a indefinição das próprias diretrizes e o açodamento para a sua implantação, este, especificamente na instituição privada confessional. As diretrizes, pelos dados obtidos na pesquisa, causaram insegurança e turbulência na ação docente e provocaram alterações pouco positivas no curso de Pedagogia. Essas diretrizes precisam de reformulações, após a análise crítica do efeito de tal legislação sobre a organização escolar, como proposto por Saviani 
(1976) e buscando o sentido de ser pedagogo não apenas para o meio acadêmico, mas, igualmente, para a sociedade que o acolhe.

Num projeto de reforma, as suas intenções de melhoria podem ser claras para os propositores, que, em geral, julgam que essas irão ocorrer, porém, tanto podem melhorar, quanto piorar, afirma Gimeno Sacristán (1998). Embora as instituições tenham que cumprir as diretrizes curriculares na elaboração dos respectivos projetos para o curso de Pedagogia, no funcionamento, nem sempre tudo ocorre como planejado e cada professor acaba fazendo uma interpretação na prática do que entende, sejam as exigências legais para a formação do pedagogo, indicando que não há consenso em torno das finalidades e objetivos propostos para a formação dos futuros pedagogos. As Diretrizes Curriculares nacionais para o curso de Pedagogia - licenciatura foi uma proposta de reforma imposta de cima que não atendeu à maioria do esperado pelos professores que iriam implantá-la. Para Rui Canário, [...] "as reformas impostas "de cima" produzem mudanças formais, mas, raramente, transformações profundas, duráveis e conformes com as expectativas dos reformadores" (2005, p. 93). A educação nos remete a ações de revolução e emancipação.

A afirmação de Larrosa \& Kohan (2002, p. 5), de que "educamos para transformar o que sabemos, não para transmitir o já sabido" guarda uma provocação e uma possibilidade que não podemos recusar a ver, diante dos dados encontrados nessa pesquisa e de tantas outras que discutem o profissional pedagogo.

A definição/indefinição do curso de Pedagogia contida nas novas diretrizes carrega vários sentidos e representações, como uma "colcha de retalhos" de posições, interesses e desejos.

Os dados obtidos junto aos docentes revelam a urgência em se esclarecer no âmbito das políticas o sentido da formação do pedagogo, compreender esta formação nos seus efeitos sobre a própria instituição formadora e os sistemas de educação básica e como produzir novos sentidos a partir do já construído. E ainda revela a impossibilidade de reconstrução da identidade do curso de Pedagogia sem a participação ativa dos professores. Nas observações das três instituições de origem dos membros 
do grupo de pesquisa, ficou evidente a resistência de alguns professores ao processo de mudança do curso determinado pelas novas diretrizes.

\section{Referências}

ALBUQUERQUE, H. M. P.; HAAS, C.M.; ARAUJO, R. M. B. Relatório final de pesquisa: O Significado de ser Pedagogo. São Paulo, 2011. (Mimeografado).

APPLE, M. Educação e Poder. Trad. Maria Cristina Monteiro e Supervisão da Trad. Tomaz T. da S. Porto Alegre: Artes Médicas, 1989.

BALL, S. J. Reformar escolas/reformar professores e os terrores da performatividade. Revista Portuguesa de Educação, v. 15, n. 2, p. 3-23, 2002.

BOURDIEU, P. El sentido práctico. Version castellana de Alvaro Pazos. Madrid: Taurus Humanidades, 1991.

BRASIL. Resolução CNE nº. 1, de 15 de maio de 2006. Institui Diretrizes Curriculares Nacionais para o Curso de Graduação em Pedagogia, licenciatura. Diário Oficial da União. Brasília, DF, 2006.

CANÁRIO, R. O que éa Escola? Um “olhar” sociológico. Porto: Porto Editora, 2005.

CHAVES, E. O. C. O curso de Pedagogia. Cadernos do Cedes. A formação do educador em debate. São Paulo: Cortez, 1981. Ano 1-Nº2.

CRUZ, G. B. Curso de Pedagogia no Brasil - História e Formação com Pedagogos Primordiais. Rio de Janeiro: Wak, 2011.

SACRISTÁN, J. G. Reformas educativas y reforma del currículo: anotaciones a partir de la experiencia española. In: WARDE, M. J. (org.). II Seminário Internacional Novas Políticas Educacionais: Críticas e Perspectivas. São Paulo: Entrelinhas, 1998. 
GOODSON, I. A Construção Social do Currículo. Lisboa: EDUCA,1997. LARROSA, J. \& KOHAN, W. Apresentação da coleção. In: RANCIÈRE, J. O mestre ignorante - cinco lições sobre a emancipação intelectual. Belo Horizonte: Autêntica, 2002. (Coleção Educação, Experiência e Sentido).

LAWN, M. Os Professores e a Fabricação de Identidade. Revista Currículo sem Fronteiras, v. 1, n. 2. p. 177-130, jul./dez. 2001. Disponível em: <http://www. curriculosemfronteiras.org/>. Acesso em: 15 ago. 2010.

LIMA, L. C. A escola como organização educativa. São Paulo: Cortez, 2001.

PABLO GENTILI, A. A. e SILVA, T. T. (Orgs). Neoliberalismo, Qualidade Total e Educação, Visões críticas. 2a Ed. Petrópolis: Vozes, 1995.

SAVIANI, D. Análise crítica da organização escolar brasileira através das leis 5.540/68 e 5.692/71. In: GARCIA, W. E. Educação Brasileira Contemporânea: organização e funcionamento. São Paulo: Mcgraw Hill do Brasil, 1976. p. 174-194.

SAVIANI, D. A Pedagogia no Brasil História e Teoria. São Paulo: Autores Associados, 2008.

PROJETO PEDAGÓGICO. Universidade Confessional. Proposta de reforma curricular da graduação do curso de Pedagogia. São Paulo, 2006. (Mimeografado).

PROJETO PEDAGÓGICO DO CURSO DE PEDAGOGIA. Universidade Federal. Licenciatura. Minas Gerais, 2008. (Mimeografado).

PROJETO PEDAGÓGICO DO CURSO DE PEDAGOGIA. Universidade Municipal. Licenciatura. São Paulo, 20011. (Mimeografado).

Recebido: 22/12/2017

Received: 12/22/2017

Aprovado: 20/04/2017

Approved: 04/20/2017 